OPEN ACCESS

Edited by:

Mariangela Caroprese, University of Foggia, Italy

Reviewed by: Juan Mosqueda,

Universidad Autónoma de Querétaro, Mexico

Barry J. Bradford,

Michigan State University, United States

*Correspondence: Jeffery A. Carroll

jeff.carroll@usda.gov

†These authors have contributed equally to this work

Specialty section

This article was submitted to Veterinary Infectious Diseases,

a section of the journal

Frontiers in Veterinary Science

Received: 26 November 2019

Accepted: 09 June 2020

Published: 04 August 2020

Citation:

Broadway PR, Mauget SA, Burdick Sanchez NC and Carroll JA (2020) Correlation of Ambient Temperature With Feedlot Cattle Morbidity and Mortality in the Texas Panhandle.

Front. Vet. Sci. 7:413 doi: 10.3389/fvets.2020.00413

\section{Correlation of Ambient Temperature With Feedlot Cattle Morbidity and Mortality in the Texas Panhandle}

\author{
Paul R. Broadway ${ }^{1 \dagger}$, Steven A. Mauget ${ }^{2 \dagger}$, Nicole C. Burdick Sanchez ${ }^{1}$ and \\ Jeffery A. Carroll ${ }^{1 *}$ \\ 1 USDA, ARS Livestock Issues Research Unit, Lubbock, TX, United States, ${ }^{2}$ United States Department of Agriculture (USDA), \\ Agricultural Research Service (ARS) Wind Erosion and Water Conservation Research Unit, Lubbock, TX, United States
}

Anecdotal data would suggest that weather patterns influence beef cattle health in feedyards, and cattle producers often associate the seasonality of some illnesses with changes in environmental temperatures. However, to our knowledge, there is little information from large-scale feeding operations and precision weather stations that establishes a link or lack thereof between weather patterns and cattle health. Additionally, we are unaware of any studies correlating other weather parameters with animal health data. Therefore, the objective of this study was to test for associations between monthly temperature variation and animal morbidity/mortality in feedlots in the Texas Panhandle. Weather data was collected from a Texas Tech University Mesonet weather station in close proximity to 19 beef cattle feedyards in the Texas Panhandle. Additionally, near real-time morbidity and mortality data was collected from those yards from 2015 to 2018. These data document a seasonal pattern relative to cattle morbidity and mortality with most health events occurring from November to January. This pattern is differentiated when comparing morbidity and mortality by listed causation (e.g., respiratory, digestive, other), and the majority of deaths over the entire time course were attributed to respiratory disease. Most cattle morbidity was documented in the winter months, most of which were classified as respiratory disorders. Additionally, an increase in health events was observed as the population of the feedyard increased. However, the overall effects of ambient temperature on cattle health were minimal and the two may not be causally linked. The initial overview of the relationships documented in this manuscript may warrant further stratification and exploration.

Keywords: cattle, feedlot, health, morbidity, mortality, temperature

\section{INTRODUCTION}

Extreme weather events such as heat waves, blizzards, ice storms, hurricanes, tornadoes, and floods pose a risk to feedlot cattle health, productivity, and well-being. For example, according to the National Weather Service, a March 1957 blizzard resulted in the death of 20\% of all cattle in the Texas and Oklahoma Panhandle (NOAA, NWS). More recently, a 2016 winter storm was responsible for the deaths of over 30,000 head in Texas and New Mexico (1). Hurricane Harvey in 2017 resulted in thousands of head reported lost or dead in addition to the millions in dollars of equipment and feed losses (2). 
Not only do these events pose a direct physical threat to cattle mortality, but also they may lead to secondary long- and short-term effects on cattle health and well-being (3). Economic losses, stemming not only directly from morbidity and mortality but also due to performance losses, may accompany weather events. Peel (4) reported that winter weather patterns may also disrupt feedlot placements and influence cattle markets. Other research reported that feed efficiency and animal performance may be negatively impacted due to climate and weather patterns (5). For example, a 2003 report suggested that heat stress could be responsible for over $\$ 2$ billion dollars in losses annually across different sectors of livestock production (6). Additionally, Hubbard et al. (7) reported that prolonged and sustained hightemperature-humidity indices (THI) can result in increased feedlot cattle mortality.

Animal caretakers and veterinarians recognize weather patterns as an important factor contributing to feedlot cattle health. In fact, a survey of feedlot veterinarians reported weather as a concern or risk factor contributing to animal health (8). Anecdotally, producers often refer to Fall as a time of year in which morbidity is most prevalent in their operations, and they often attribute these health problems to extreme fluctuations in temperature throughout the day. There is also data to support claims that air temperature can influence cattle health $(9,10)$. Specifically, Cusack et al. (11) asserted that daily weather fluctuations may impact bovine respiratory disease (BRD) incidence. Data from Ribble et al. (12) further confirm seasonality of illness, reporting November feedlot placement as a risk factor for BRD when compared to other months.

Overall, literature correlating weather patterns to realtime morbidity and mortality is sparse and much of the previous literature does not cover a wide time frame or sample population. Therefore, the following data retrospectively characterize weather patterns for 4 years and its relationship to the corresponding incidence of morbidity and mortality in feedlot cattle in the Texas Panhandle using precision temperature-monitoring systems in close proximity to beef cattle feedlots.

\section{MATERIALS AND METHODS}

Ethical approval was not required according to national/local legislation because the described study did not use live animals. Rather, this manuscript describes a retrospective analysis of cattle data acquired from a database of U.S. feedyard data.

\section{Feedyard and Meteorological Data}

In order to obtain real-time (daily) morbidity and mortality data and associated population and demographic data from feedlots, data were acquired from Elanco Knowledge Solutions (EKS) Benchmark Performance Program (Elanco Knowledge Solutions, Lenexa, KS, 2019). This database compiles real-time data acquisition from 254 beef cattle feedyards within the

Abbreviations: BRD, bovine respiratory disease; DTR, daily temperature range; TMIN, minimum temperature; TMAX, maximum temperature; EKS, Elanco Knowledge Solutions.
United States. For this analysis, data were only collected from feedlots in the Texas Panhandle. Specifically, beef cattle feedyards were included in the sample population within a $96.6-\mathrm{km}$ radius of Hereford, TX. Daily data was collected from the date range: January 1, 2015, to December 31,2018, based on the date of closeout for a feedlot defined lot. These feedlots were selected to prevent no more than $40 \%$ of the cattle on any given date to be owned by a single feedlot. Feedlot names, locations, and lot numbers were coded using a random-number generator as to blind data analysts and maintain anonymity using the RAND and RANK functions of Excel. Data were also sorted to remove any lots within a feedlot which took $>30$ days to fully place or fill. Data included both steers and heifers but were limited to only include beef-type cattle and exclude calf-feds and dairy beef. Data from lots fed $>400$ days were excluded, and cattle placed in the lot were required to have an incoming weight $<1,000$ lbs. $(453.59 \mathrm{~kg})$. During the 48 -month period, the number of yards contributing to morbidity and mortality counts during any month varied from 3 to 16 (Figure 1A). The monthly population, morbidity, and mortality counts calculated here were derived from daily head counts for lots in those yards in a given month. The total number of lots in a month's available data were generally proportional to the monthly total head count (Figure 1B) and varied from 24 in December 2018 to 219 in January 2018.

Concurrent to feedlot data, weather data was derived from the West Texas Mesonet [WTM; (13)] weather station at Hereford, TX. Daily minimum (TMIN) and maximum (TMAX) temperatures were derived from archived 5-min WTM Hereford temperature records. Given the possible association of cattle health with extreme daily shifts in temperature, daily temperature range (DTR) values (i.e., maximum minus minimum daily temperatures) were also derived from the 5-min Hereford temperatures. The resulting daily records were then averaged into monthly TMIN, TMAX, and DTR values for each month of January 2015 to December 2018.

For purposes of these analyses, morbidity was defined as a first hospitalization or treatment event in an attempt to better attribute weather patterns to initial illness and not confound morbidity as an additional treatment in response to a possible previously acquired illness or treatment event. Mortality was simply defined as a recorded death. Attribution of morbidity and mortality reports is assumed accurate as having entered into the real-time database and does not require clinical and/or pathological burden of proof which allows for possible misdiagnoses within the dataset. Furthermore, morbidity and mortality were stratified by causation. Aside from the aforementioned sorting and selection criteria, no other stratification of weather and/or morbidity and mortality data was performed, and all data were collapsed into similar time categories (e.g., month within year) prior to analysis.

\section{Statistical Methods}

Monthly population counts for each lot in a feedyard were estimated as the average of the lot's daily head-in-pen counts during the month. Monthly total population, or total head count, was considered the sum of the average head counts of all lots in all feedyards during the month. Monthly death counts for 


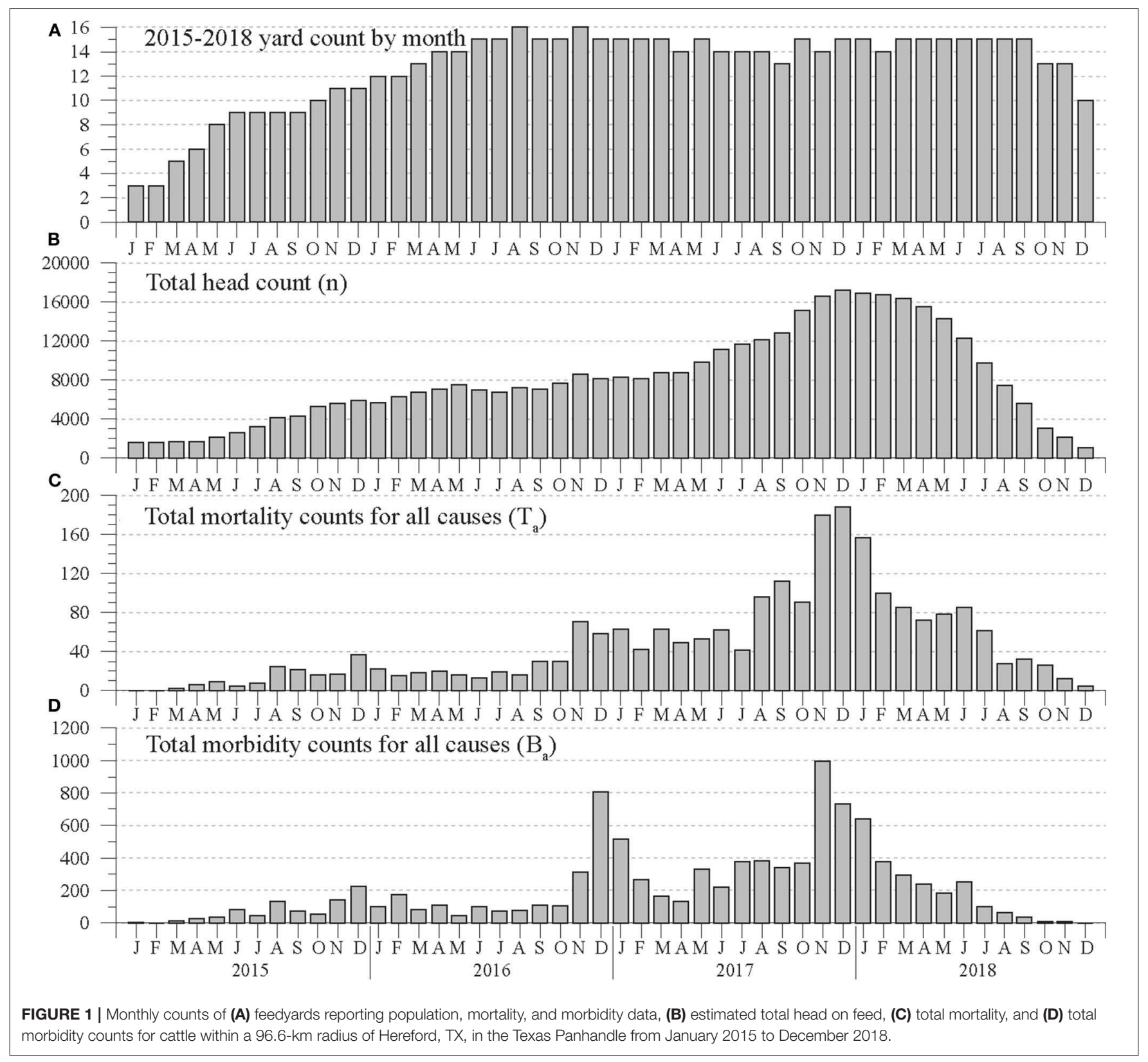

all causes in a lot are the sum of deaths reported daily during the month due to all causes for the lot. In addition, daily death counts classified as respiratory, digestive, and other causes for each lot were summed into monthly counts for those causes. The feedyards' total monthly death counts for all (a), respiratory (r), digestive (d), and other (o) causes were tallied as the sum across all lots in all feedyards.

Because the number of feedyards reporting data from January 2015 to December 2018 varied widely, monthly total population counts varied proportionally (Figure 1B). As a result, mortality and morbidity counts were normalized to monthly percentages based on the same month's total population count. Thus, a month's mortality percentage $\left(\%_{t}\right)$ was calculated as

$$
\%_{t}=100.0 * \mathrm{t}=100.0 * \frac{\mathrm{T}}{\mathrm{n}},
$$

where $\mathrm{T}$ is a monthly mortality count and $\mathrm{n}$ is the month's total population count. Similarly, morbidity percentages $\left(\%_{\mathrm{b}}\right)$ were calculated as

$$
\%_{b}=100.0 * \mathrm{~b}=100.0 * \frac{\mathrm{B}}{\mathrm{n}},
$$

where $\mathrm{B}$ is a monthly morbidity count. For the three reported causes, monthly mortality $\left(\%_{\mathrm{tr}}, \%_{\mathrm{td}}, \%_{\mathrm{to}}\right)$ and morbidity $\left(\%_{b r}, \%_{b d}, \%_{b o}\right)$ percentages were calculated based on the $t$ $\left(t_{r}, t_{d}, t_{o}\right)$ and $b\left(b_{r}, b_{d}, b_{o}\right)$ ratios of the corresponding mortality $\left(\mathrm{T}_{\mathrm{r}}, \mathrm{T}_{\mathrm{d}}, \mathrm{T}_{\mathrm{o}}\right)$ and morbidity counts $\left(\mathrm{B}_{\mathrm{r}}, \mathrm{B}_{\mathrm{d}}, \mathrm{B}_{\mathrm{o}}\right)$. The significance 


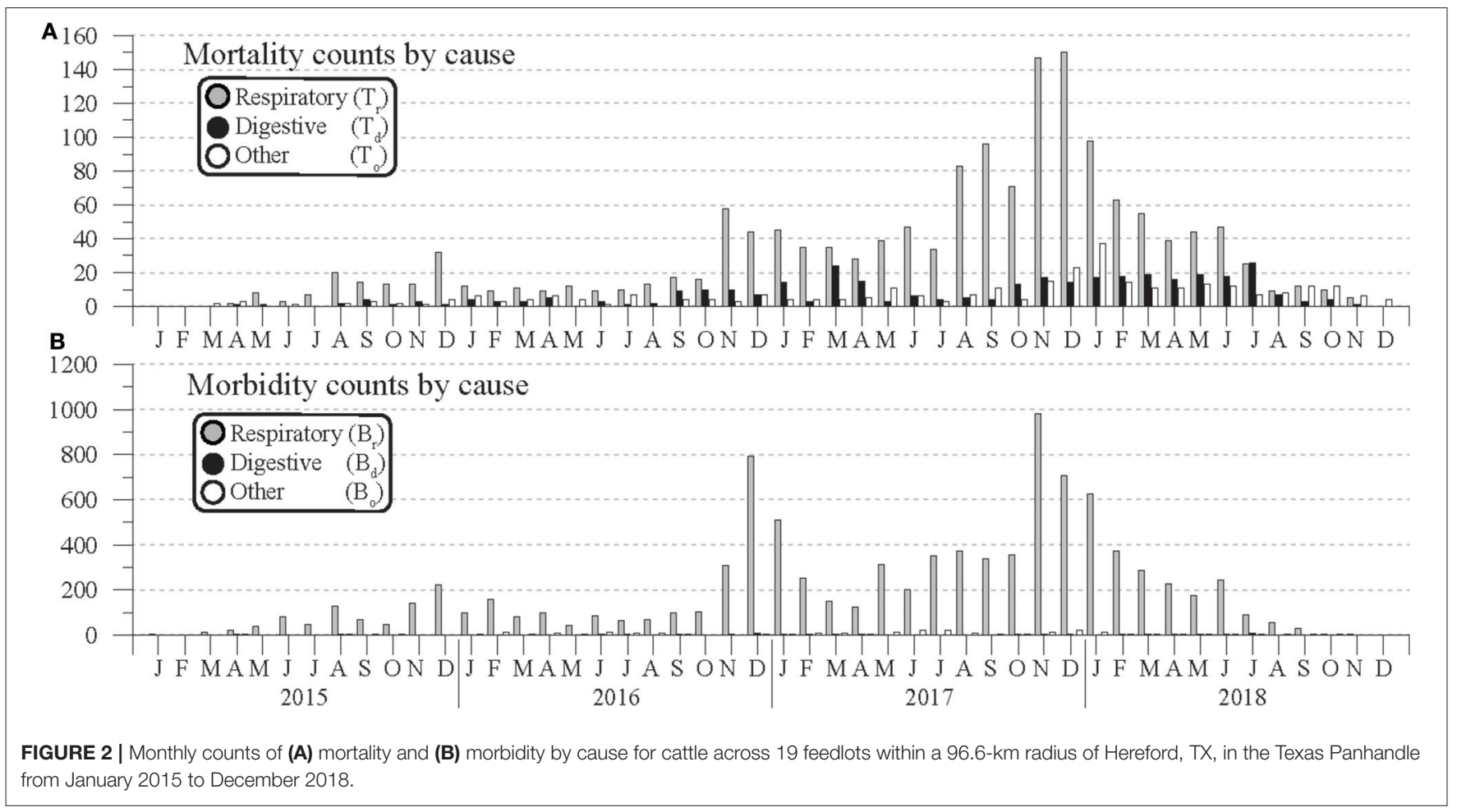

of differences between ratios was determined by comparing uncertainty intervals based on the standard deviation of a large sample of proportions, e.g.,

$$
\sigma_{t}=\sqrt{\frac{t *(1-t)}{n}}
$$

and conducting two-proportion Z-tests. Thus, for example, to compare two mortality ratios $t_{1}$ and $t_{2}$,

$$
Z\left(t_{1}, t_{2}\right)=\frac{t_{1-t_{2}}}{\sqrt{\hat{t}(1-\hat{t}) *\left(\frac{1}{n_{1}}+\frac{1}{n_{2}}\right)}}
$$

where

$$
\hat{t}=\frac{T_{1}+T_{2}}{n_{1}+n_{2}}
$$

The summation of monthly population, mortality and morbidity counts, and the calculation of percentages in the EKS Benchmark data were calculated using R (RStudio version 1.1.383) statistical software (14). The Equation (5) standard deviations and Equation (6) Z statistics were calculated using Fortran code, while the $\mathrm{R}$ cor.test and $\mathrm{lm}$ functions were used to calculate Pearson correlations and linear regressions. Significance of correlations and $\mathrm{Z}$ statistics were defined at a 95\% confidence level $(p=0.05)$ or better.

\section{RESULTS}

\section{Variation in Cattle Population, Mortality, and Morbidity}

Monthly total population counts are shown in Figure 1B, while Figures 1C,D show total mortality $\left(T_{a}\right)$ and morbidity $\left(B_{a}\right)$ counts for all causes. From 2015 to 2018, total estimated head on feed increased from 1,579 in January 2015 to a maximum of 17,156 in December 2017, then decreased to a minimum of 1,078 in December 2018. During the 48-month period, the $T_{a}$ and $B_{a}$ counts varied in a manner roughly proportional to total population. Mortality counts rose from 2 in March 2015 to a peak of 188 in December 2017, then decreased to 4 in December 2018. After relatively constant morbidity counts under 200 during most of 2016, $B_{a}$ counts increased to 807 in December 2016, decreased during the spring and summer of 2017, then rose to 995 in November 2017.

Mortality and morbidity counts by cause are plotted in Figures 2A,B. For both cases, respiratory causes were the most commonly reported, most noticeably in morbidity counts. Because these counts might be expected to track total head count, the corresponding Equations (1a,b) morbidity and mortality percentages were calculated and are plotted in Figures 3A,B. This normalization shows that respiratory mortality and morbidity counts are not strictly proportional to total head count. For example, $B_{r}$ counts in Figure 2B peak in Nov. 2017, but Figure 3B's respiratory morbidity percentages peak in December 2016. Also, in Figure 2A the November 2017 respiratory mortality counts are more than double those of November 2016, but the Figure $3 \mathrm{~A}$ respiratory percentages for those months 


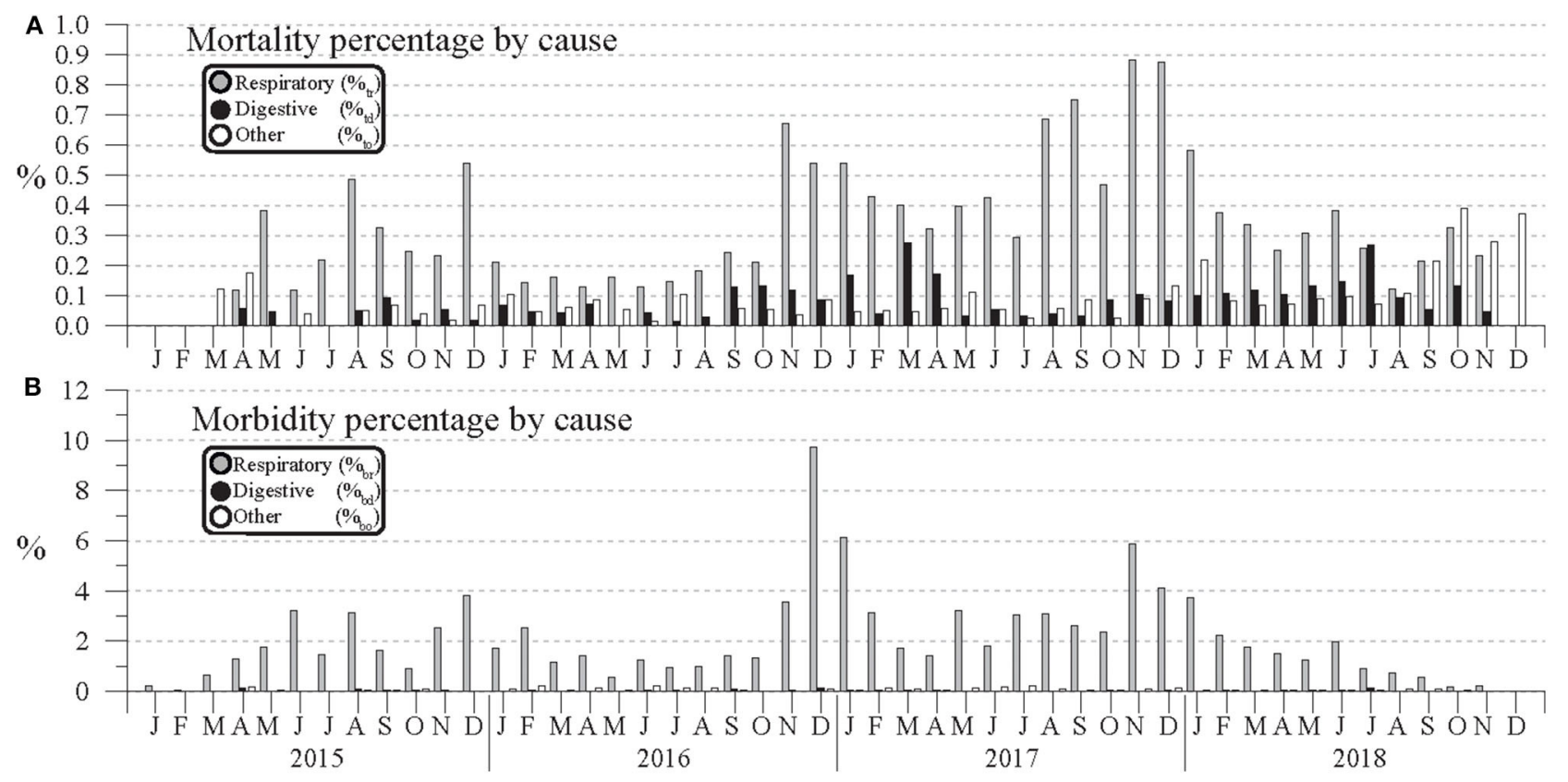

FIGURE 3 | Monthly (A) mortality and (B) morbidity percentage by cause for cattle across 19 feedlots within a 96.6-km radius of Hereford, TX, in the Texas Panhandle from January 2015 to December 2018.

are more comparable. During 2015-2019, monthly respiratory mortality percentages $\left(\%_{\text {tr }}\right)$ peaked in the winter months, with the three highest values occurring in November $2016(0.67 \%)$, November 2017 (0.88 \%), and December 2017 (0.87 \%). Similarly, the three highest monthly morbidity percentages occurred in December 2016 (9.7\%), January 2017 (6.1\%), and November 2017 (5.9 \%) from respiratory causes. By contrast, no clear seasonal variation in morbidity or mortality due to digestive or other causes seems apparent.

When the Equation (1) mortality, morbidity, and population counts for each cause are aggregated by month across all 4 years, the resulting annual cycles of $\%_{t}$ and $\%_{b}$ in Figures 4A,B show significantly increased percentages for respiratory causes during the winter months. The $\pm 1.96^{*} \sigma$ uncertainty bars of the Figure $4 \mathrm{~A}$ respiratory mortality percentages $(\%$ tr $)$ for each month suggest significantly elevated death rates in November and December relative to October and January. Although the November and December $t_{\mathrm{r}}$ ratios are statistically indistinct $(Z=0.372, p=0.710)$, the $Z$ statistic for the difference in November and October ratios is $5.686(p<0.0001)$ and the statistic for the December and January ratios is 3.709 ( $p<$ $0.001)$. Although the January $t_{r}$ ratio is significantly lower than December's, the January $95 \%$ uncertainty range for $\%_{\operatorname{tr}}$ does not overlap with the intervals of February through July. The $\mathrm{Z}$ statistics comparing the January $t_{r}$ ratio with the ratios of those months are all significantly different at $99 \%$ confidence interval $(p<0.01)$, which suggests that January might be included in a winter respiratory mortality season.

In Figure 4A, a secondary peak in respiratory mortality rate is also seen in August and September, whose $t_{r}$ ratios are not significantly different at a 95\% confidence level $(p=0.237)$.
However, the August $t_{\mathrm{r}}$ ratio is significantly different from the July ratio $(p<0.001)$, and the September ratio is significantly different from October's $(p<0.05)$. Although Figure 4A shows evidence of seasonality in respiratory mortality, the $1.96^{*} \sigma$ uncertainty bars for digestive and other causes consistently overlap, which indicates the lack of significant seasonal variation. Those uncertainty intervals also fall clearly below those of the same month's \% $\%_{\text {tr }}$ intervals, which shows that overall respiratory mortality was significantly greater than that from digestive or other causes during 2015-2018.

In Figure 4B's annual cycles of morbidity percentages, the values associated with respiratory causes ( $\%$ br $)$ clearly dominate those from digestive or other causes. Similar to Figure 4A's mortality percentages, the highest $\%$ br values occur in November (4.34\%), December (5.34\%), and January (3.81 \%). However, given the small $1.96^{*} \sigma$ intervals relative to those values, all of those percentages are significantly distinct from one another. Unlike the respiratory mortality percentages in Figure 4A, there is no evidence of a significant increase in respiratory morbidity during August and September.

\section{Correlation of Monthly Respiratory Mortality and Morbidity Rates vs. Monthly Temperature Conditions}

In Figure 5, relationships between monthly respiratory mortality $\left(\%_{\text {tr }}\right)$ and morbidity $\left(\%_{\text {br }}\right)$ percentages and monthly population and temperature conditions during 2015-2018 are explored via scatterplots. The monthly mean minimum temperature (TMIN), maximum temperature (TMAX), and daily temperature range (DTR) values for Hereford TX during 2005-2018 can be found 

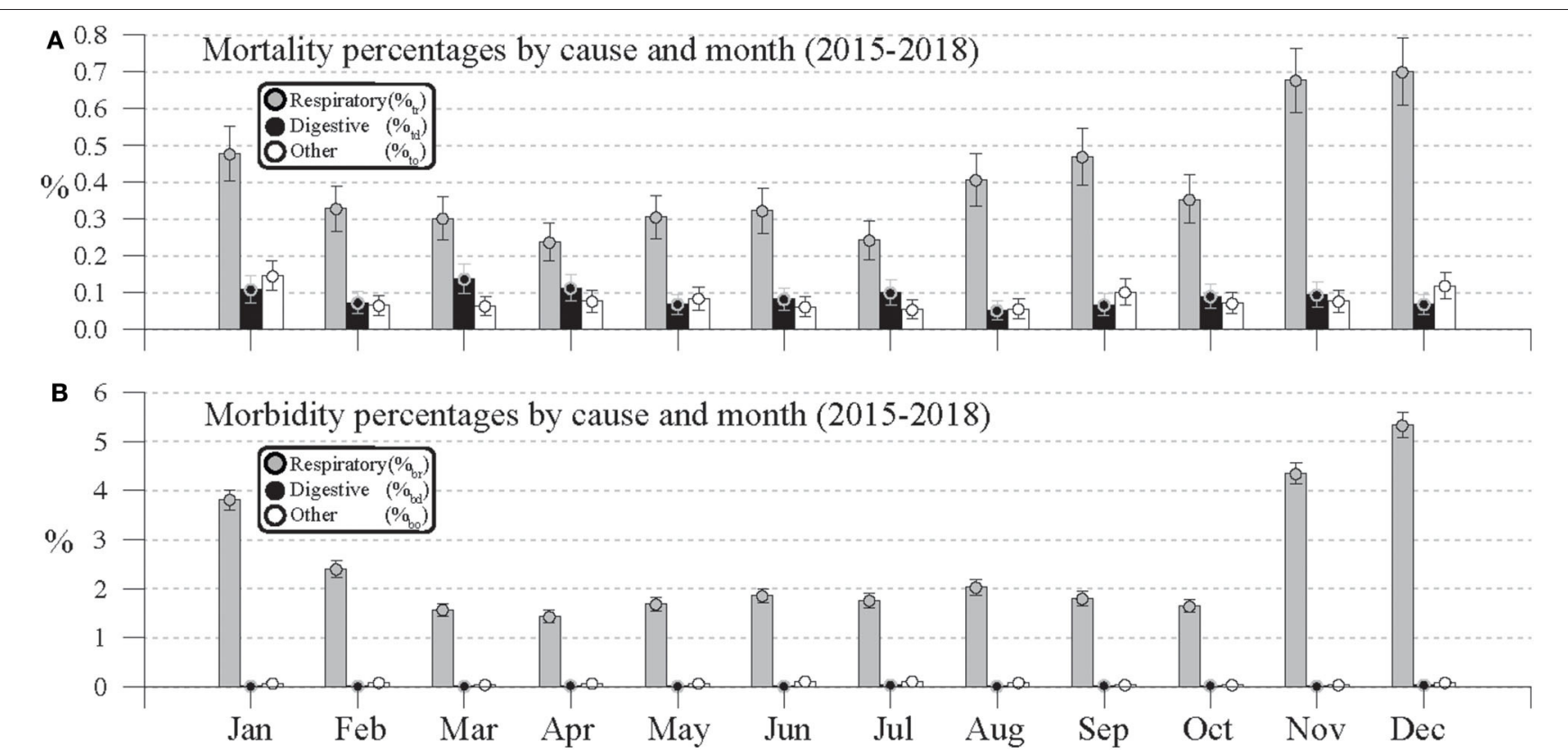

FIGURE 4 | Monthly (A) mortality percentage and (B) morbidity percentages for respiratory, digestive, and other causes calculated from mortality, morbidity, and total head counts aggregated by month during January 2015 to December 2018.

in Table 1 and are representative of the region's cold semi-arid climate conditions. During 2015-2018, Hereford TMIN varied between $-5.8^{\circ} \mathrm{C}$ (December 2017 ) to $22.6^{\circ} \mathrm{C}$ (July 2018) while TMAX varied between $7.8^{\circ} \mathrm{C}$ (January 2015) to $37.6^{\circ} \mathrm{C}$ (July 2018). Monthly average DTR varied between $11.0^{\circ} \mathrm{C}$ (October 2018) and $19.4^{\circ} \mathrm{C}$ (February 2016). As noted in section Feed yard and Meteorological Data, Hereford monthly temperature conditions are considered to be representative of the temperature conditions of the feedyards considered here, which lie within a 96.6-km radius of the Hereford WTM site.

Figures 5A-D plot monthly $\%_{\operatorname{tr}}$ for each month vs. monthly total head (a), TMIN (b), TMAX (c), and DTR (d). Figures $\mathbf{5 E}-\mathbf{H}$ are similar scatterplots comparing monthly $\%_{\text {br }}$ vs. the same sequence of population and monthly mean temperature variables. Given the increased mortality and morbidity in Figures 4A,B during November, January, and February, the Figure 5 scatterpoints are colored to distinguish winter (November-December-January), spring (February-March-April), summer (May-June-July), and fall (August-September-October) months in both plot sequences.

Figure 5A shows a roughly linear scatter between monthly respiratory mortality percentages and population, with the 12 winter scatterpoints suggesting a semi-linear relationship. By contrast, the relatively random scatter of mortality percentages with TMIN and TMAX shows no obvious overall linear or nonlinear relationship (Figures 5B,C). However, those plots show that mortality percentages above $0.5 \%$ occurred in the winter or fall months. The two fall months with greater percentages occurred in August and September of 2017. Similarly, no clear relationship between DTR and mortality percentages over all seasons was seen in Figure 5D, but there was a tendency for winter mortality percentages to increase as mean monthly DTR increased during the winter months.

To test the significance of the Figures 5A-D scatter patterns, Pearson correlation values were calculated between monthly $\%_{\text {tr }}$ and concurrent TMIN, TMAX, DTR, and total head values (Table 2). The correlations showing significance at a $95 \%$ or better confidence level $(p<0.05)$ are generally consistent with the scatter patterns noted above. Correlations of $\%$ tr percentages with population were significant over all 48 monthly data points $(r=0.637 ; p<0.001)$ and for all seasons except summer. The correlation between winter mortality and population is Table 2's highest correlation $(r=0.877)$ and is significant at a $99.9 \%$ confidence level $(p<0.001)$. Apart from the correlations with population, the only other significant correlation was between $\%_{\text {tr }}$ and DTR during the winter months $(r=0.755 ; p<0.01)$.

Table 2's significant winter DTR vs. total head correlations suggest that winter respiratory mortality rates might be better explained through the combined influence of those two factors. However, a linear regression that estimates winter $\%_{\text {tr }}$ based on both of those variables explains the same amount of variance $\left(r^{2}\right.$ $=0.769$ ) that total head count alone does. Thus, the combined regression effect of head count and DTR is not additive. A regression based on DTR alone explains less $\%_{\text {tr }}$ variance $\left(r^{2}=\right.$ 0.569 ) than head count. Also, it is possible that the significant correlation between winter DTR and $\%_{\operatorname{tr}}$ is due to chance. In addition to being significantly correlated with $\%_{\text {tr }}$, winter DTR is even more highly correlated with winter head count $(r=$ $0.864, p<0.001)$. Total head count vs. DTR correlations during the remaining spring $(r=0.022, p=0.947)$, summer $(r=$ $0.560, p=0.058)$, and fall $(r=0.205, p=0.522)$ seasons are all insignificant, which might be expected between total head 


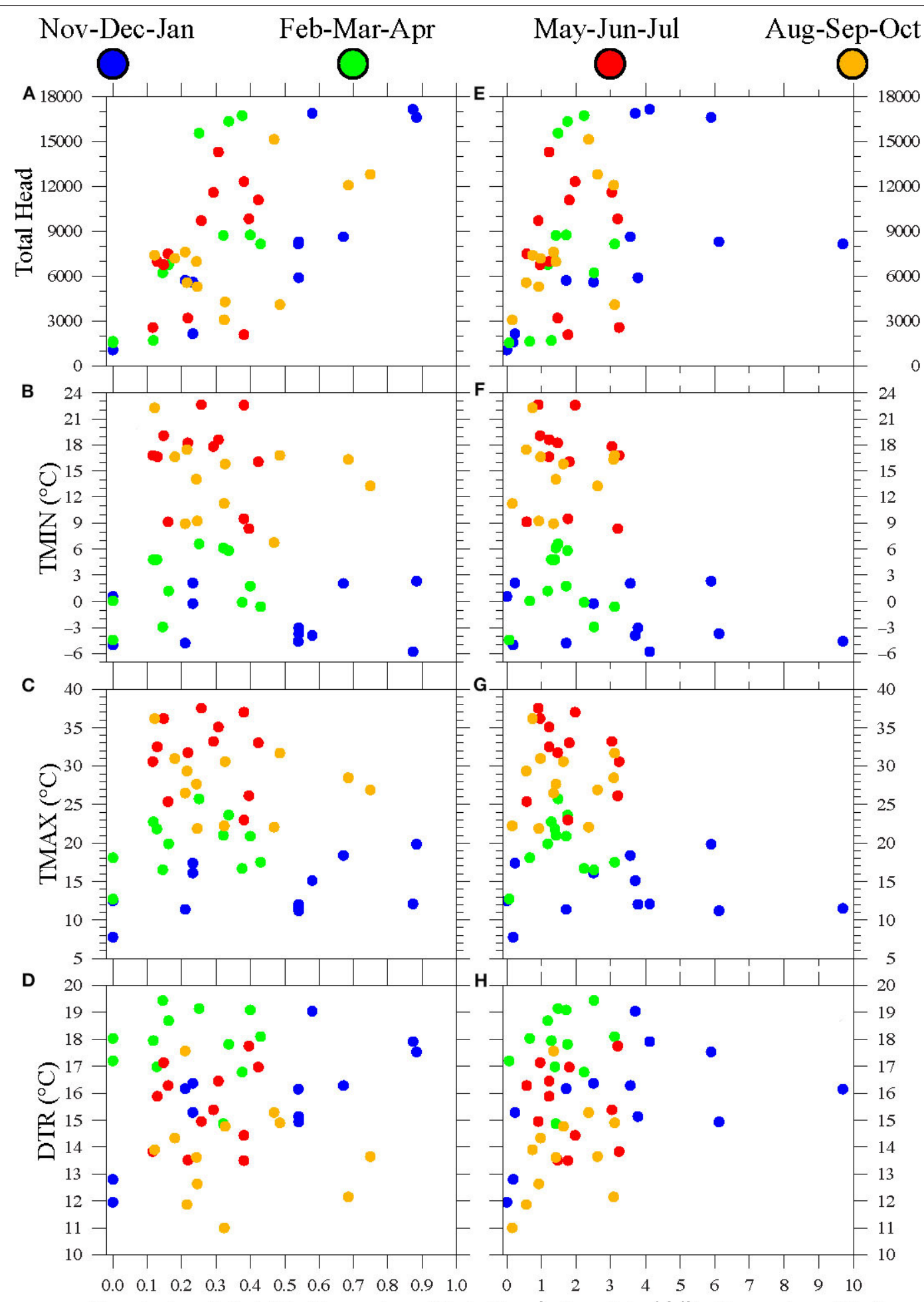

Respiratory Mortality Percentage $\left(\%_{\mathrm{tr}}\right)$ Respiratory Morbidity Percentage $\left(\%_{\mathrm{br}}\right)$

FIGURE 5 | Scatterplots of (A) monthly respiratory mortality percentage (\%tr) vs. monthly total head, (B) \%tr vs. average monthly minimum temperatures (TMIN), (C) \%tr vs. average monthly maximum temperatures (TMAX), (D) \%tr vs. average monthly daily temperature range (DTR), (E) \%tr vs. monthly total head, (F) monthly respiratory morbidity percentage (\%br) vs. average monthly minimum temperatures (TMIN), (G) \%br vs. average monthly maximum temperatures (TMAX), and (H) \%br vs. average monthly maximum daily temperature range (DTR). All monthly head counts, \%tr, and \%br values were calculated across 19 feedyards within a $96.6-\mathrm{km}$ radius of Hereford, Texas, during January 2015 to December 2018. All monthly temperature values were calculated from daily data from the Hereford Mesonet station. 
TABLE 1 | Monthly average minimum temperature (Tmin), maximum temperature (Tmax), and daily temperature range (DTR) in degrees centigrade ( $\left.{ }^{\circ} \mathrm{C}\right)$ for Hereford Texas during 2005-2018.

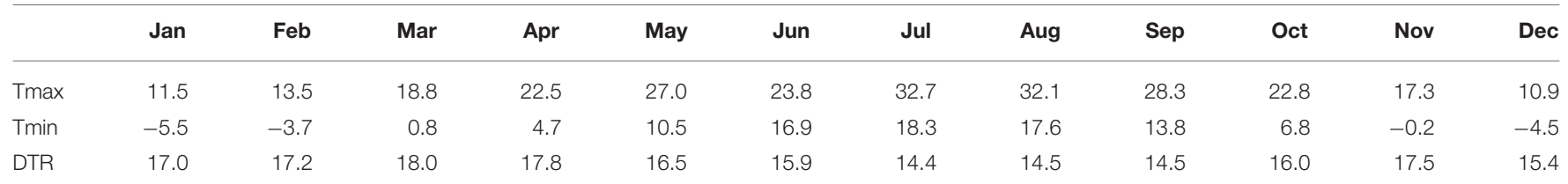

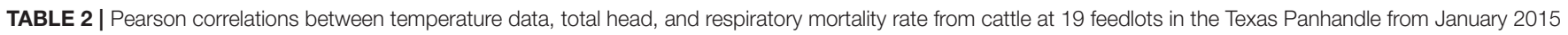
to December 2018.

\begin{tabular}{|c|c|c|c|c|c|}
\hline Time period & $\mathrm{DF}^{\mathrm{e}}$ & $\operatorname{Tmin}^{f}$ & $\operatorname{Tmax}^{\mathrm{g}}$ & $D_{T R}^{h}$ & Total head \\
\hline Annual (Jan-Dec) & 46 & -0.121 & 0.115 & 0.073 & $0.637^{\star \star \star *}$ \\
\hline Winter $^{a}$ & 10 & 0.003 & 0.428 & $0.755^{\star \star}$ & $0.877^{\star \star \star}$ \\
\hline Spring ${ }^{b}$ & 10 & 0.296 & 0.277 & -0.072 & $0.721^{\star \star}$ \\
\hline Summer ${ }^{\mathrm{c}}$ & 10 & -0.138 & -0.102 & 0.124 & 0.454 \\
\hline Fall $^{d}$ & 10 & -0.162 & -0.217 & -0.122 & $0.581^{\star}$ \\
\hline
\end{tabular}

a Winter: November-December-January.

b Spring: February-March-April.

'Summer: May-June-July.

${ }^{d}$ Fall: August-September-October.

${ }^{e} D F$ : degrees of freedom.

${ }^{f}$ Tmin: minimum temperature.

${ }^{9}$ Tmax: maximum temperature.

${ }^{h}$ DTR: daily temperature range.

${ }^{\star \star \star \star} P<0.001$.

${ }^{\star \star} P<0.01$.

${ }^{\star} P<0.05$.

TABLE 3 | Correlations between temperature data, total head, and respiratory morbidity rate from cattle at 19 feedlots in the Texas Panhandle from January 2015 to December 2018.

\begin{tabular}{|c|c|c|c|c|c|}
\hline Time period & DF & $\operatorname{Tmin}^{\mathrm{e}}$ & $T_{\max }^{f}$ & DTR $^{g}$ & Total head \\
\hline Annual (Jan-Dec) & 46 & $-0.312^{*}$ & -0.284 & 0.205 & $0.377^{\star \star}$ \\
\hline Winter ${ }^{a}$ & 10 & -0.228 & 0.066 & 0.473 & 0.548 \\
\hline Spring $^{b}$ & 10 & 0.003 & 0.074 & 0.203 & 0.475 \\
\hline Summer ${ }^{\mathrm{C}}$ & 10 & -0.174 & -0.209 & -0.096 & -0.028 \\
\hline Fall $^{d}$ & 10 & -0.052 & 0.068 & 0.294 & 0.554 \\
\hline
\end{tabular}

a'Winter: November, December, January.

bspring: February, March, April.

'Summer: May, June, July.

${ }^{d}$ Fall: August, September, October.

e Tmin: minimum temperature.

${ }^{f}$ Tmax: maximum temperature.

${ }^{g}$ DTR: daily temperature range.

${ }^{\star \star} P<0.01$.

${ }^{*} P<0.05$

count and a weather variable that should have no influence on feedyard stocking rates. Thus, Table 2's significant winter DTR vs. $\%_{\text {tr }}$ correlation may be due to a chance coincidence between increasing monthly winter total head counts and increasing winter DTR during 2015-2018 and is a possible example of type I error.

The Figures 5E-H scatterplots compare monthly \% $\%_{b r}$ with concurrent total head count, TMIN, TMAX, and DTR show similar but weaker relationships than their $\%_{\operatorname{tr}}$ counterparts in Figures 5A-D. The corresponding Pearson correlations and their statistical significance are found in Table 3. The Figure 5E scatter shows a significant relationship $(r=0.377, p<0.01)$ for $\%_{\text {br }}$ to increase with total head over all seasons, but a stronger correlation was found between $\%_{\text {tr }}$ and total head in Table 2. Aside from a low but significant negative correlation $(r=-0.312$, $p=0.03$ ) between $\%_{b r}$ and TMIN over all seasons, there were no significant effects of varying TMIN or TMAX on $\%_{\mathrm{br}}$ during any season. However, in Figures 5F,G, percentages above $4.0 \%$ 
are limited to the winter months. Monthly \% $\%_{\mathrm{br}}$ showed no clear or significant relationship with DTR (Figure 5H). Although the Table 3 correlations between $\%_{b r}$ and total head during the winter $(r=0.548, p=0.065)$, spring $(r=0.475, p=0.118)$, and fall months $(r=0.554, p=0.062)$ are higher than the all-month correlation, they are not significant at a $95 \%$ confidence level.

\section{DISCUSSION}

Feedyard cattle morbidity with respect to respiratory disease peaked at $9.7 \%$ in the current study, whereas data from NAHMS (15) reported respiratory disease affecting $16.2 \%$ of all cattle in the United States. Data from smaller feedyards $(1,000$ to 8,000 head capacity) more closely resembles data from this study suggesting only $9.0 \%$ of cattle from those locations were affected by respiratory disease. Data from the NAHMS study also suggests that placement of cattle $>317.5 \mathrm{~kg}$ reduced the percentage of cattle affected by respiratory illness from 21.2 to $8.8 \%$ compared to their smaller counterparts entering the feedyard at a weight $<317.5 \mathrm{~kg}$. Reported mortalities by month peaked at $0.88 \%$ in the data utilized for this study, whereas Loneragan et al. (16) reported an average mortality of $0.0126 \%$ utilizing data from 1994 to 1999. A 1978-1979 study in Canada also reported a mortality percentage of $0.134 \%$ across all types of cattle from 81 farmers (17). The fact that the greatest amount of morbidity and mortality were associated with respiratory disease was not a surprise based on previously reported data (15). The variation between data in these studies may be partially explained when considering the referenced studies are of national scope in comparison to a small geographical area of the Texas Panhandle. Regional management practices and breed type may vary greatly and partially explain the observed differences in health occurrence percentages.

Overall, morbidity and mortality were greatest in winter months. In addition to a tendency for increased winter mortality and morbidity, the Figure $\mathbf{3 A}$ respiratory mortality percentages, and to a lesser extent the respiratory morbidity percentages of Figure 3B, appear generally proportional to the Figure 1C monthly population counts. Stated otherwise, respiratory death and morbidity percentages were found to increase as the population of the feedyards increased. By contrast, similar variation was not evident in the digestive and other death and morbidity percentages. Monthly mortality percentages classified as digestive or other causes remained relatively stable across the 4 years, with the exception of elevated percentages of digestive-related deaths in March 2017 and July 2018, and increased percentages of deaths classified as other from October to December 2018 (Figure 3A). Although respiratory death and morbidity counts might be expected to track total population counts, their percentages should also be expected to be approximately constant unless there is a link between respiratory problems and population. However, here a proportionality seems evident between population and morbidity and mortality percentages. This is intuitively reasonable: as yards and lots become more densely populated, percentages of respiratory transmission, morbidity, and mortality might be expected to increase due to a possible increase in the probability of exposure. Data from a retrospective mortality study also reported respiratory disorders as the primary cause of death, accounting for greater than half of all mortality cases (16) followed by digestive causes of mortality.

The lack of seasonal patterns associated with digestive morbidity and mortality was surprising. Anecdotal evidence suggests that cold weather may alter feed delivery and intake patterns, and the changes in temperatures in the spring and fall may result in overeating and acidotic conditions. Another point of interest was the lack of a correlation between heat stress and morbidity and mortality. Vogel and Parrott (18) reported increased mortality from digestive issues from June to November of 0.18 to $0.47 \%$, and similar to this study, digestive mortality was greatest in November and December. Conversely Elam (19) reported the greatest incidence of digestive issues the feedlot occurring during warmer weather possibly associated with a change in eating behavior. Concurrently, Mader et al. (20) and Hahn and Mader (21) also described alterations in feeding behavior, growth performance, and mortality percentages during periods of increased temperatures.

Anecdotal observations of health issues during extreme temperature swings were partially confirmed in this study as a link was observed between winter DTR and respiratory mortality percentage. This correlation is further confirmed as Cusack et al. (11) similarly asserted daily weather fluctuations and the incidence of BRD. However, these fluctuations do not correspond to temperature fluctuations in other seasons, most notably being absent in spring months. A study conducted by Cusack et al. (9) reported associations between BRD morbidity and mortality and weather in Australian feedlot cattle. Specifically, the authors found an association between minimum daily temperature and BRD morbidity. However, the aforementioned study focused on one feedlot over a two-month period, which contrasts with the current study which analyzed data on 19 feedyards across 4 years. As shown previously, however, DTR and stocking density are closely correlated in winter months over the 4-year period. Given the high correlation of these causally unrelated variables, making an association between winter DTR and morbidity based on our data may be an example of TYPE I error.

Trends from this analysis indicate that as the total head on feed increases, the percentages of respiratory-related morbidity increased (i.e., the greater the stocking density, the greater the risk of illness). Data from NAHMS (15) reported 9\% of respiratory disease in cattle located in feedlot housing between 1,000 and 8,000 head; however, the percentages increased to $17.2 \%$ of cattle affected in feedlot housing $>8,000$ head. Yet, due to the possible design differences between the sampled feedyards, it may not fully explain the increased morbidity percentage. Increased contact between animals due to proximity or increased numbers of animals sharing a space such as a feed bunk or processing area may influence the incidence of disease (22). Additionally, commingling of cattle from different sources, often referred to as high-risk cattle, may increase the probability of a respiratory disease occurrence; however, the authors were unable to distinguish calf source from the database utilized for this analysis. This manuscript does not address many potential confounding variables including, but not 
limited to, gender, breed type, age, misdiagnosis, management practices, etc., but attempts to objectively describe the data from a high vantage point evaluating the relationships of ambient temperature, morbidity, and mortality. Undoubtedly, these data will warrant future analysis to further stratify these data to recognize specific patterns that producers may be able to use to predict feedlot morbidity and mortality in relationship to seasonal weather patterns.

\section{CONCLUSIONS}

Overall, there is no strong correlation between ambient temperature and cattle health. However, both morbidity and mortality percentages increase during winter months, with the majority of the causality associated with respiratory issues. Additionally, increases in populations of cattle within a feedlot resulted in increased percentage of health events. There was no correlation of health patterns with summer temperature patterns. Collectively, these data report correlations that both coincide and contradict with dogmas surrounding climate and health. Further exploration across different regions with the incorporation of more cattle and feedlot demographic data may be warranted to further elucidate the relationship between ambient temperature patterns and feedlot cattle health and well-being.

\section{DATA AVAILABILITY STATEMENT}

The datasets generated for this study are available on request to the corresponding author.

\section{ETHICS STATEMENT}

Ethical approval was not required according to national/local legislation because the described study did not use live animals.

\section{REFERENCES}

1. Carr A. Dairy cow death toll to surpass 30,000 in Texas, New Mexico due to winter storm Goliath. The Weather Channel (2016). Available online at: https://weather.com/news/news/dairy-cows-winter-storm-goliathtexasnew-mexico

2. Associated Press. Texas cotton hit hardest as harvey ag losses top $\S 200 \mathrm{M}$. AP News (2017). Available online at: https://apnews.com/ d5ce5dde463141a399abb6b0420b821c/Texas-cotton-hit-hardest-as-Harveyag-losses-top-\$ $\backslash$ protect $\backslash \mathrm{T} 1 \backslash$ textsection $\$ 200 \mathrm{M}$.

3. Webster A. Weather and infectious disease in cattle. Vet Record. (1981) 108:183-7. doi: 10.1136/vr.108.9.183

4. Peel D. Winter Weather Impacts Cattle Markets Vol. 2019. Drovers (2019).

5. Hahn GL. Weather and climate impacts on beef cattle. Br Res Program Progr Rep. (1985) 2:85-9.

6. St-Pierre N, Cobanov B, Schnitkey G. Economic losses from heat stress by US livestock industries. J Dairy Sci. (2003) 86:E52-77. doi: 10.3168/jds.S0022-0302(03)74040-5

7. Hubbard K, Stooksbury D, Hahn G, Mader T. A climatological perspective on feedlot cattle performance and mortality related to the temperaturehumidity index. J Produc Agric. (1999) 12:650-3. doi: 10.2134/jpa1999. 0650

8. Terrell S, Thomson D, Wileman B, Apley M. A survey to describe current feeder cattle health and well-being program recommendations made by
Rather, this manuscript describes a retrospective analysis of cattle data acquired from a database of U.S. feedyard data.

\section{AUTHOR CONTRIBUTIONS}

$\mathrm{PB}$, JC, and SM initiated the initial study design. PB and SM collected the data. Data was analyzed by SM. The manuscript was written by $\mathrm{PB}, \mathrm{NB}$, and SM. All authors reviewed drafts of the manuscript and provided approval prior to submission.

\section{ACKNOWLEDGMENTS}

Mention of trade names or commercial products in this article is solely for the purpose of providing specific information and does not imply recommendation or endorsement by the U.S. Department of Agriculture. The U.S. Department of Agriculture (USDA) prohibits discrimination in all its programs and activities on the basis of race, color, national origin, age, disability, and, where applicable, sex, marital status, familial status, parental status, religion, sexual orientation, genetic information, political beliefs, or reprisal, or because all or part of an individual's income is derived fromany public assistance program (not all prohibited bases apply to all programs). Persons with disabilities who require alternative means for communication of program information (Braille, large print, audiotape, etc.) should contact USDA's TARGET Center at (202) 720-2600 (voice and TDD). To file a complaint of discrimination, write to USDA, Director, Office of Civil Rights, 1400 Independence Avenue, S.W., Washington, D.C. 20250-9410, or call (800) 7953272 (voice) or (202) 720- 6382 (TDD). USDA is an equal opportunity provider and employer. The authors would like to thank J. W. Dailey (USDAARS- LIRU) for his excellent technical support. All figures were produced using Generic Mapping Tools (23).
Feedlot Veterinary Consultants in the United States and Canada. Bovine Pract. (2011) 45:140-8. doi: 10.21423/bovinevol48nolp53-60

9. Cusack P, McMeniman N, Lean I. Feedlot entry characteristics and climate: their relationship with cattle growth rate, bovine respiratory disease and mortality. Aust Vet J. (2007) 85:311-6. doi: 10.1111/j.1751-0813.2007.00184.x

10. Cernicchiaro N, Renter D, White B, Babcock A, Fox J. Associations between weather conditions during the first 45 days after feedlot arrival and daily respiratory disease risks in autumn-placed feeder cattle in the United States. $J$ Ani Sci. (2012) 90:1328-37. doi: 10.2527/jas.2011-4657

11. Cusack P, McMeniman N, Lean I. The medicine and epidemiology of bovine respiratory disease in feedlots. Austr Vet J. (2003) 81:480-7. doi: 10.1111/j.1751-0813.2003.tb13367.x

12. Ribble CS, Meek AH, Janzen ED, Guichon PT, Jim GK. Effect of time of year, weather, and the pattern of auction market sales on fatal fibrinous pneumonia (shipping fever) in calves in a large feedlot in Alberta (1985-1988). Can J Vet Res. (1995) 59:167.

13. Schroeder JL, Burgett W, Haynie K, Sonmez I, Skwira G, Doggett A, et al. The West Texas mesonet: a technical overview. J Atmosph Oceanic Technol. (2005) 22:211-22. doi: 10.1175/JTECH-1690.1

14. R Core Team. R: A Language and Environment for Statistical Computing; $R$ Foundation for Statistical Computing. Vienna (2017). Available online: https:// www.r-project.org (accessed on March 28, 2017).

15. NAHMS. United States Department of Agriculture, Animal and Plant Health Inspection Service, Veterinary Services, National 
Animal Health Monitoring System. Feedlot (2011). Available online at: https://www.aphis.usda.gov/aphis/ourfocus/animalhealth/monitoringand-surveillance/nahms/nahms_feedlot_studies/ut/p/z1/1ZLLcoIwFIafxQXLkh N0ALsDyggt2FalYjYM1nCZAcKQWGb69I1tN72ImE0mme87yfkTRFCMSJOl XkqStaklVzviJ4ssbMAc4aDhXuHwfLm_ oNn6AChgbafQPA4c7C9Bjm7 Nljuyghd19cATxG5zn_xdOlvos3SxLY_18b5cGZYMM4fA MhwftLB8gEtS50whyRNhXFTdlkDMVNWtQ8ySg9VEwkXBwPJeXyMmSw3 LP2DZzLe3UJOD3IL-Bv4iN6ziu2_oeVrOfmrK5jma0o5167OR2IUTLbx VQoO97NWcsr6j6ymoF_lMKxgWKf5KoraMoitDbO2XT_XW5NZk8gHd6NGI/\#feedlot11.

16. Loneragan GH, Dargatz DA, Morley PS, Smith MA. Trends in mortality ratios among cattle in US feedlots. $J$ Am Vet Med Assoc. (2001) 219:1122-7. doi: 10.2460/javma.2001. 219.1122

17. Martin S, Meek A, Davis DG, Thomson R, Johnson J, Lopez A, et al. Factors associated with mortality in feedlot cattle: the Bruce County Beef Cattle Project. Can J Comp Med. (1980) 44:1.

18. Vogel G, Parrott C. Mortality survey in feedyards: the incidence of death from digestive, respiratory, and other causes in feedyards on the great plains. Comp Cont Educ Pract Vet. (1994) 16:227-34.

19. Elam C. Acidosis in feedlot cattle: practical observations. J Anim Sci. (1976) 43:898-901. doi: 10.2527/jas1976.43 $4898 \mathrm{x}$
20. Mader T, Holt S, Hahn G, Davis M, Spiers D. Feeding strategies for managing heat load in feedlot cattle. J Anim Sci. (2002) 80:2373-82. doi: $10.2527 / 2002.8092373 \mathrm{x}$

21. Hahn G, Mader T. Heat waves in relation to thermoregulation, feeding behavior and mortality of feedlot cattle. In: Proceedings Fifth International Livestock Environment Symposium. Bloomington, MN (1997).

22. Callan RJ, Garry FB. Biosecurity and bovine respiratory disease. Vet Clin North Am Food Anim Pract, (2002) 18:57-77. doi: 10.1016/S0749-0720(02)00004-X

23. Wessel P, Smith WHF, Scharroo R, Luis JF, Wobbe F. Generic mapping tools: improved version released. EOS Trans. (2013) 94:409-10. doi: 10.1002/2013EO450001

Conflict of Interest: The authors declare that the research was conducted in the absence of any commercial or financial relationships that could be construed as a potential conflict of interest.

Copyright (c) 2020 Broadway, Mauget, Burdick Sanchez and Carroll. This is an open-access article distributed under the terms of the Creative Commons Attribution License (CC BY). The use, distribution or reproduction in other forums is permitted, provided the original author(s) and the copyright owner(s) are credited and that the original publication in this journal is cited, in accordance with accepted academic practice. No use, distribution or reproduction is permitted which does not comply with these terms. 